\title{
Cancer Worry Distribution and Willingness to Undergo Colonoscopy at Three Levels of Hypothetical Cancer Risk-A Population-Based Survey in Sweden
}

\author{
Carolina Hawranek 1,*(D), Johan Maxon ${ }^{1} \mathbb{D}$, Andreas Andersson ${ }^{1} \mathbb{D}$, Bethany Van Guelpen ${ }^{1,2} \mathbb{D}^{\mathrm{D}}$, \\ Senada Hajdarevic ${ }^{3,4}{ }^{(D}$, Barbro Numan Hellquist ${ }^{1}$ (D) and Anna Rosén ${ }^{1}$ (D)
}

1 Department of Radiation Sciences, Oncology, Umeå University, SE-901 87 Umeå, Sweden; johan@maxon.se (J.M.); anden_16@hotmail.com (A.A.); bethany.vanguelpen@umu.se (B.V.G.); barbro.hellquist@onkologi.umu.se (B.N.H.); anna.rosen@umu.se (A.R.)

2 Wallenberg Centre for Molecular Medicine, Umeå University, SE-901 87 Umeå, Sweden

3 Department of Nursing, Umeå University, SE-901 87 Umeå, Sweden; senada.hajdarevic@umu.se

4 Department of Public Health and Clinical Medicine, Family Medicine, Umeå University, SE-901 87 Umeå, Sweden

* Correspondence: carolina.hawranek@umu.se; Tel.: +46-76-69-60-648

check for updates

Citation: Hawranek, C.; Maxon, J.; Andersson, A.; Van Guelpen, B.; Hajdarevic, S.; Numan Hellquist, B.; Rosén, A. Cancer Worry Distribution and Willingness to Undergo Colonoscopy at Three Levels of Hypothetical Cancer Risk-A Population-Based Survey in Sweden. Cancers 2022, 14, 918. https:// doi.org/10.3390/cancers14040918

Academic Editor: Ettore Bidoli

Received: 13 January 2022

Accepted: 9 February 2022

Published: 12 February 2022

Publisher's Note: MDPI stays neutral with regard to jurisdictional claims in published maps and institutional affiliations.

Copyright: () 2022 by the authors. Licensee MDPI, Basel, Switzerland. This article is an open access article distributed under the terms and conditions of the Creative Commons Attribution (CC BY) license (https:// creativecommons.org/licenses/by/ $4.0 /)$.
Simple Summary: Cancer worry is a known health concern in cancer patients and people with a genetic predisposition to cancer. We measured how worried people, in general, are about developing cancer to describe levels in non-affected individuals. In total, 943 respondents completed a survey containing the Cancer Worry Scale (CWS) and hypothetical questions asking if they would attend a colonoscopy screening at a 5, 10, or 70 percent lifetime risk of developing bowel cancer. Unaffected individuals scored a mean of 9.46 on the six-item CWS. Women scored significantly higher than men (9.91 vs. 9.06). Women and parents had higher cancer worry than men and people without children when ruling out differences in education, age, and country of birth. People who worried more were also more inclined to undergo a colonoscopy screening, and intention increased with higher levels of hypothetical risk. These data may be helpful in future work on cancer worry and cancer prevention.

\begin{abstract}
Purpose: We describe levels of cancer worry in the general population as measured with the Cancer Worry Scale (CWS) and investigate the association with colonoscopy screening intentions in three colorectal cancer risk scenarios. Methods: The data were sourced through a population-based survey. Respondents $(n=943)$ completed an eight-item CWS and questions on colonoscopy screening interest at three hypothetical risk levels. Results: Respondents without a personal cancer history $(n=853)$ scored 9.46 on the six-item CWS (mean, SD 2.72). Mean scores were significantly higher in women (9.91, SD 2.89) as compared to men (9.06, SD 2.49, $p<0.001)$. Linear regression showed higher cancer worry in women and those with children when controlling for education, age group, and country of birth. High cancer worry (six-item CWS mean $>12$ ) was identified in $25 \%$ of women and in $17 \%$ of men. Among those, $71 \%$ would attend a colonoscopy screening compared to $52 \%$ of those with low cancer worry ( $p<0.001,5 \%$ CRC-risk). Conclusions: The distribution of cancer worry in a general population sample showed higher mean scores in women, and levels overlapped with earlier findings in cancer-affected samples. Respondents with high cancer worry were more inclined to undergo a colonoscopy screening, and intention increased with higher levels of hypothetical risk.
\end{abstract}

Keywords: cancer; oncology; cancer worry; cancer worry scale; colonoscopy; colorectal cancer; early detection of cancer; patient reported outcome measures

\section{Introduction}

The fear of developing cancer, or the fear of cancer recurrence, is a known health concern in cancer-affected individuals, cancer survivors, and individuals with an increased 
hereditary risk of cancer [1-5]. Besides a negative impact on quality of life, mental health, and psychosocial wellbeing [2], cancer worry has been shown to modulate health-related behaviors such as lifestyle choices and screening participation [6-8]. Research suggests that cancer worry mainly facilitates, but in some cases also hinders, screening uptake [5,7-10]. Worry levels seem to correlate with a subjectively perceived risk of cancer [11], but the relationship between cancer worry and screening behavior seems to be complex and likely non-linear $[7,12]$.

A commonly used instrument to assess cancer worry is the Cancer Worry Scale (CWS). The scale was originally developed as a four-item measure of frequency and severity of fear of developing cancer and has mostly been administered on high-risk individuals to assess how worry impacts mood and daily functioning [13-15]. The CWS was later expanded to include six and, finally, eight items [4,14], and has also been applied to assess fear of cancer recurrence [2]. The six-item CWS has been validated in cancer patients, and the suggested cut-off has been compared with the 42-item inventory on fear of cancer recurrence [4]. Although the six-item CWS show convergent and divergent validity and high internal consistency to detect fear of cancer, there is a lack of norm data from population-based samples. Moreover, to date, there is no standard definition of clinically significant cancer worry and no universally accepted approach to measuring this [3-5,14,16-18].

With the lack of normative population data and an ambiguous relationship between cancer worry and screening intentions, we addressed the following research questions:

(1) How is cancer worry distributed in the general population in Sweden?

(2) Are cancer worry and the intention to undergo a colonoscopy screening associated?

\section{Materials and Methods}

We used a cross-sectional design administering an 8-item Cancer Worry Scale and three items on screening intentions in a population-based sample of the public in Sweden. Characteristics and subgroups were compared and tested for statistical significance. Results are presented separately for the 6-item CWS and the 8-item CWS and are separated for samples with and without individuals who had personal cancer experiences.

\subsection{Data Collection}

Survey data were sourced through an electronic questionnaire in an online research infrastructure administered by the Laboratory of Opinion Research (LORE) at Gothenburg University [19]. A number of subjects were selected to enable quantitative subgroup analyses. Subjects invited to this study had previously been randomly selected from the Swedish Population Register to join the Swedish Citizen Panel. The invitation included neutral text, non-revealing as to the topic of investigation, an estimate of how long the survey would take to complete, and how the collected data would be used and handled confidentially (Supplementary file 2). The invitation was personally signed by the managing researcher and with the full name of the institution. Data were collected between the 12th of September and 7th of October 2018. Two electronic reminders were sent to non-responders on days 6 and 14 after initial survey distribution. Our questions were part of a larger set of questions with which we have previously reported on the public's attitudes towards hereditary cancer risk communication [20].

\subsection{Measurements}

To measure cancer worry, respondents were asked to complete the 8-item four-point Likert scale (supporting information, Tables S1 and S2). A total score ranged from 8 to 32 , with a higher total score indicating greater worry about cancer and/or greater impact on mood and daily functioning. The adopted 8-item English Cancer Worry Scale [14] was translated into Swedish and then independently translated back into English to test retention of meaning and semantic coherence. Piloting of the questionnaire resulted in minor rephrasing. Due to the uncertain internal validity of questions 7 and $8[9,21]$, results are presented with and without these last two items. The main text was based on results 
from the more widely used 6-item CWS in individuals without a personal cancer history, however, full 6- and 8-item results for all respondents are presented in the supporting material. For an analysis using cut-offs between low and high cancer worry, the CWS scores of each dataset were grouped into low $(\leq 11)$ and high worry $(\geq 12)$ for the 6-item CWS and low $(\leq 13)$ and high worry $(\geq 14)$ for the 8-item CWS, according to previously defined cut-offs $[4,9]$.

To investigate whether cancer worry affects cancer screening intention, we asked about respondents' preferences to participate in a colonoscopy screening in three different hypothetical scenarios (supporting information, Table S3). Each scenario included a colorectal cancer risk level with a corresponding screening recommendation: an average population risk of $5 \%$ with one-time colonoscopy, a moderately increased lifetime risk of $10 \%$ with a colonoscopy every fifth year, or a greatly increased lifetime risk of $70 \%$ with colonoscopy every second year. Intention to undergo a colonoscopy was rated on a four-point Likert scale where "Yes, absolutely" and "Yes, I think so" were considered as positive responses and "No, I don't think so" and "No, absolutely not" were considered as negative responses.

Self-reported information about gender, age, education level, country of birth, and parental status was acquired from the Citizen Panel database. In addition, one background question addressed personal cancer history: "Have you ever been diagnosed with cancer?" Response options included "Yes", "No", or "Prefer not to say".

\subsection{Statistical Methods}

Categorical variables were described with counts and proportions and compared using chi-square tests. Continuous variables were described with medians, means, and standard deviations (SD) and were compared using $t$-tests and one-way ANOVA tests. To analyze factors associated with cancer worry, we applied a multivariable linear regression model with the 6-item CWS score as the dependent variable. Checking the model assumptions, we found that the distribution of the CWS score was skewed; therefore, the CWS score was log-transformed in the model. A $p$-value below 0.05 was considered statistically significant. The statistical software package R, version 3.5.2, was used for data analysis and creation of figures [22].

\section{Results}

Of the 1800 subjects invited, 943 respondents completed all eight cancer worry items (52\%). Gender distribution did not differ between respondents and non-respondents, but older age, higher educational level, being born in Sweden, and having children were overrepresented among respondents (Table S5). Among all respondents, 853 reported that they had no personal cancer history (90\%). Moreover, 82 reported a previous cancer diagnosis and eight did not want to disclose a personal cancer history.

\subsection{Distribution of Cancer Worry and Possible Determinants}

\subsubsection{CWS Scores in Respondents without a Personal Cancer History}

In respondents without a personal cancer history, the mean six-item CWS score was 9.46 (SD 2.72, Table 1). Both mean CWS scores and the proportion of respondents scoring in the higher interval were higher for women (9.91, SD 2.89 and 25\%) compared to men (9.06, SD 2.49 and 17\%). In the univariable analyses, CWS scores did not differ by age, educational level, having children, or country of birth (Table 1).

In a multivariable linear regression with log-transformed CWS scores as an outcome variable, female gender $(9.3 \%, p<0.001)$ and having children $(4.9 \%, p=0.04)$ were associated with increased cancer worry. Higher education $(4.6 \%, p=0.05)$ had a borderline significant association with lower cancer worry while age and country of birth did not (Figure 1). 
Table 1. Six-item CWS score in participants without personal cancer history in a population-based sample $(n=853)$.

\begin{tabular}{|c|c|c|c|c|c|c|c|c|}
\hline & \multirow[b]{2}{*}{ Subgroup } & \multirow{2}{*}{$\begin{array}{c}\text { Total } \\
\mathrm{N}\end{array}$} & \multicolumn{2}{|c|}{ 6-Item CWS Score } & \multicolumn{4}{|c|}{ 6-Item CWS Score Interval } \\
\hline & & & $\begin{array}{c}\text { Median } \\
(\text { Min-Max) }\end{array}$ & $\begin{array}{l}\text { Mean } \\
\text { (Stand. } \\
\text { Dev.) }\end{array}$ & $\begin{array}{c}p \text {-Value } \\
t \text {-Test/ } \\
\text { ANOVA }\end{array}$ & $\begin{array}{c}\text { Low } \\
\text { (CWS Score } \\
6-11) \\
\mathrm{N}(\%)^{\dagger}\end{array}$ & $\begin{array}{c}\text { High } \\
\text { (CWS Score } \\
12-24) \\
\text { N }(\%)^{\dagger}\end{array}$ & $\begin{array}{c}p \text {-Value } \\
\text { Chi-Square } \\
\text { Test }\end{array}$ \\
\hline Total & - & 853 & $9(6-22)$ & $9.46(2.72)$ & & $674(79)$ & $179(21)$ & \\
\hline \multirow[t]{3}{*}{ Gender } & Women & 403 & $9(6-22)$ & $9.91(2.89)$ & & $301(75)$ & $102(25)$ & \\
\hline & Men & 450 & $9(6-19)$ & $9.06(2.49)$ & & $373(83)$ & 77 (17) & \\
\hline & & & & & $p<0.001^{* * *}$ & & & $p=0.004^{* *}$ \\
\hline \multirow[t]{7}{*}{ Age } & $18-29$ & 123 & $9(6-19)$ & $9.28(2.78)$ & & $98(80)$ & $25(20)$ & \\
\hline & $30-39$ & 135 & $9(6-22)$ & $9.65(3.18)$ & & $102(76)$ & $33(24)$ & \\
\hline & $40-49$ & 153 & $9(6-17)$ & $9.45(2.76)$ & & $120(78)$ & $33(22)$ & \\
\hline & $50-59$ & 141 & $9(6-17)$ & $9.67(2.62)$ & & $107(76)$ & $34(24)$ & \\
\hline & $60-69$ & 176 & $9(6-17)$ & $9.41(2.47)$ & & $144(82)$ & $32(18)$ & \\
\hline & $70-74$ & 125 & $9(6-18)$ & $9.28(2.53)$ & & $103(82)$ & $22(18)$ & \\
\hline & & & & & $p=0.74$ & & & $p=0.61$ \\
\hline \multirow[t]{4}{*}{ Education $\ddagger$} & Lower & 344 & $9(6-22)$ & $9.50(2.69)$ & & $267(78)$ & 77 (22) & \\
\hline & Middle & 271 & $9(6-21)$ & $9.60(2.81)$ & & $213(79)$ & $58(21)$ & \\
\hline & Higher & 234 & $9(6-17)$ & $9.24(2.67)$ & & $190(81)$ & 44 (19) & \\
\hline & & & & & $p=0.31$ & & & $p=0.58$ \\
\hline Country & Sweden & 785 & $9(6-22)$ & $9.43(2.69)$ & & $622(79)$ & $163(21)$ & \\
\hline of birth $\S$ & Other & 14 & $9(6-19)$ & $9.68(3.08)$ & & $46(77)$ & $14(23)$ & \\
\hline \multirow{4}{*}{ Children II } & & & & & $p=0.55$ & & & $p=0.75$ \\
\hline & Yes & 540 & $9(6-21)$ & $9.59(2.65)$ & & $419(78)$ & $121(22)$ & \\
\hline & No & 308 & $8(6-22)$ & $9.21(2.80)$ & & $252(82)$ & $56(18)$ & \\
\hline & & & & & $p=0.06$ & & & $p=0.17$ \\
\hline
\end{tabular}

${ }^{\dagger}$ Numbers may not sum to 100 due to rounding. ${ }^{\ddagger}$ Education categorized into Lower (high school or less), Middle (up to 2 years at post-secondary level), or Higher (over 2 years at post-secondary level). NA $(n=4)$ not included. \$ Country of birth with response options: Sweden, Europe, or Outside Europe clustered into Sweden and Other. NA $(n=8)$ not included. "I Respondents' answers to the question, "Do you have children?" NA $(n=5)$ not included. ${ }^{* *}$ Indicate a $p$-value of $\leq 0.01$ and ${ }^{* * *}$ indicate a $p$-value of $\leq 0.001$.

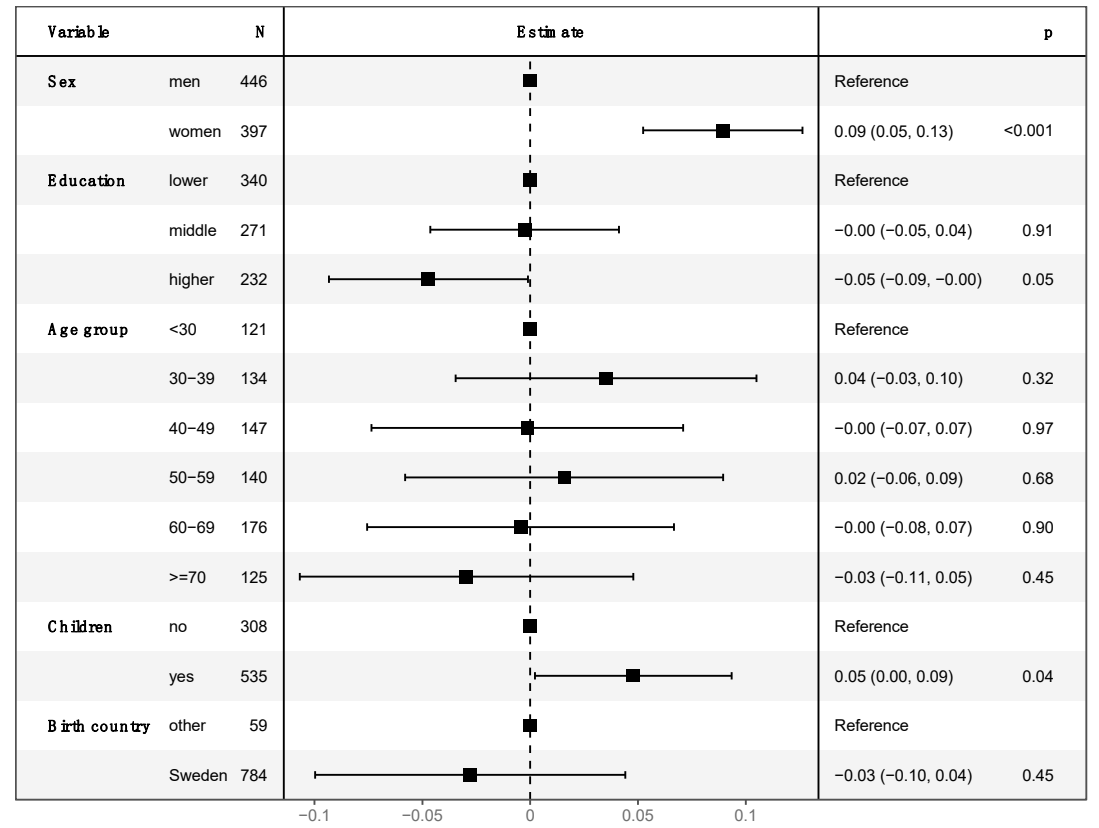

Figure 1. Multivariable linear regression of log-transformed 6-item CWS score in respondents without personal cancer history. The model is adjusted for sex (men/women), education level (lower, middle, higher), age group ( $<30$ years $/ 30-39$ years $/ 40-49$ years $/ 50-59$ years $/ 60-69$ years $/>69$ years), children (yes/no), and country of birth (Sweden/other). The outcome of 6-item CWS score was log-transformed due to its skewed distribution. Intercept estimate was $2.172178(p<0.001)$. 
In the eight-item CWS, results were similar to those from the six-item CWS, but total scores were higher due to two additional items (supporting information, Figure S1, Table S4).

\subsubsection{CWS Score in the Full Population-Based Sample}

Mean CWS scores and the proportion of respondents scoring in the higher interval were significantly higher in women (10.10, SD 3.09 and 27\%) as compared to men (9.17, SD 2.59 and $18 \%, p<0.001$ and $p=0.002$, respectively). Respondents with a personal cancer history scored significantly higher on the six-item CWS than the larger unaffected group (mean 11.00 vs. 9.46, $p<0.001$ ). CWS scores did not differ by age, educational level, having children, or country of birth (supporting information, Table S7). In the eight-item CWS, the results were similar to those from the six-item CWS, but total scores were higher due to two additional items (supporting information, Figure S2, Table S8).

\subsection{Cancer Worry and Intention to Participate in Colorectal Cancer Screening}

The distribution of cancer worry scores was skewed to the left (mean 9.08, median 8) among respondents with no or little intention to undergo a colonoscopy compared to those positive toward colonoscopy (mean 10.09, median 10, $t$-test, $p<0.001$ ) (Figure 2).

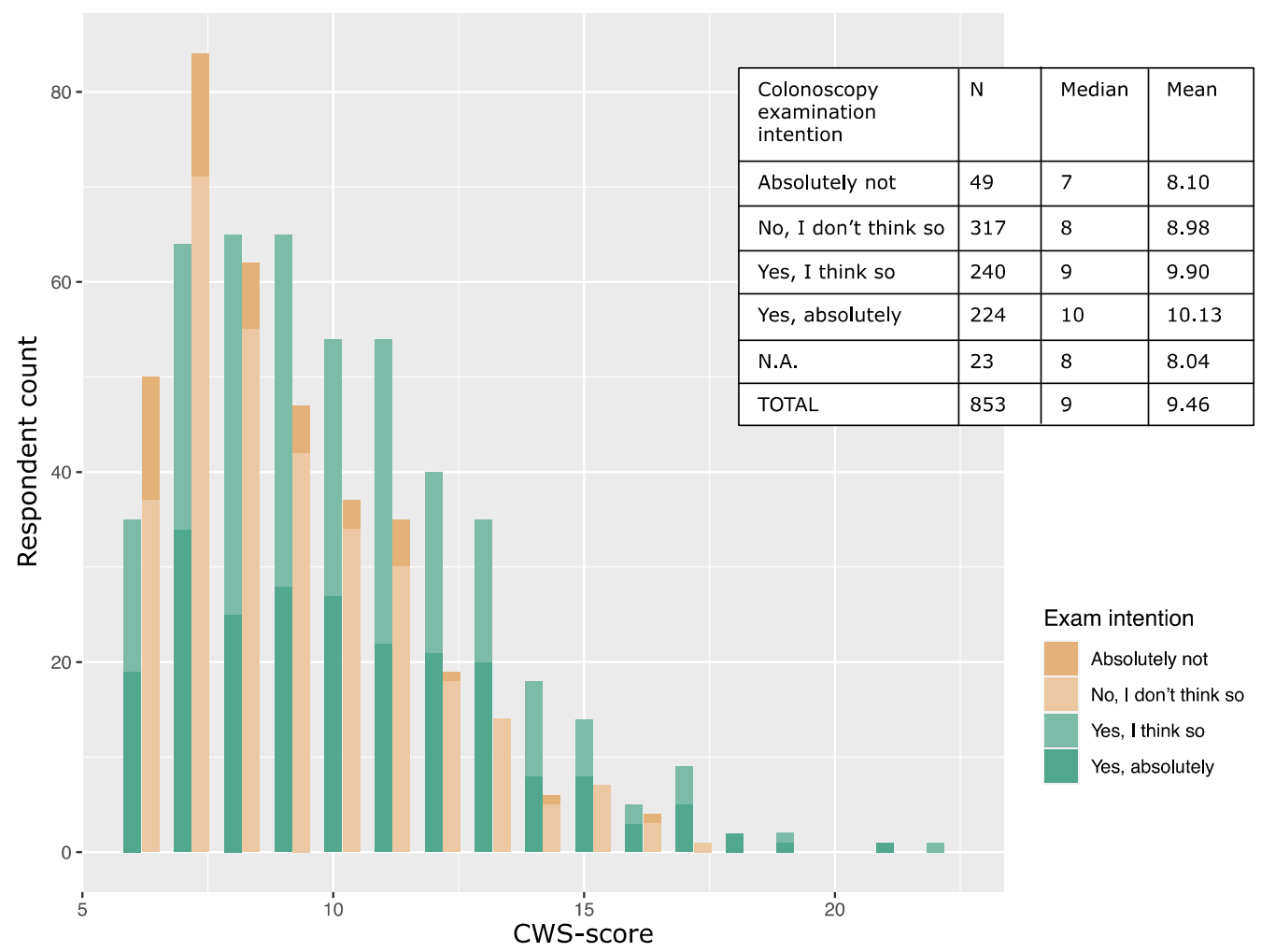

Figure 2. Distribution of cancer worry score grouped by intention to undergo a colonoscopy. Six-item CWS scores among respondents with intention to undergo a colonoscopy (green bars, $n=464$, median 10 , mean 10.01) and respondents without intention to undergo a colonoscopy (brown bars, $n=366$, median 8 , mean 8.86 ) in the scenario of having a $5 \%$ lifetime colorectal cancer risk.

The proportion of respondents who intended to undergo a colonoscopy increased with the increasing level of hypothetical colorectal cancer risk (Chi2 test, $p<0.001$ ). This trend remained when the data were stratified into high and low cancer worry subgroups (Figure 3). 


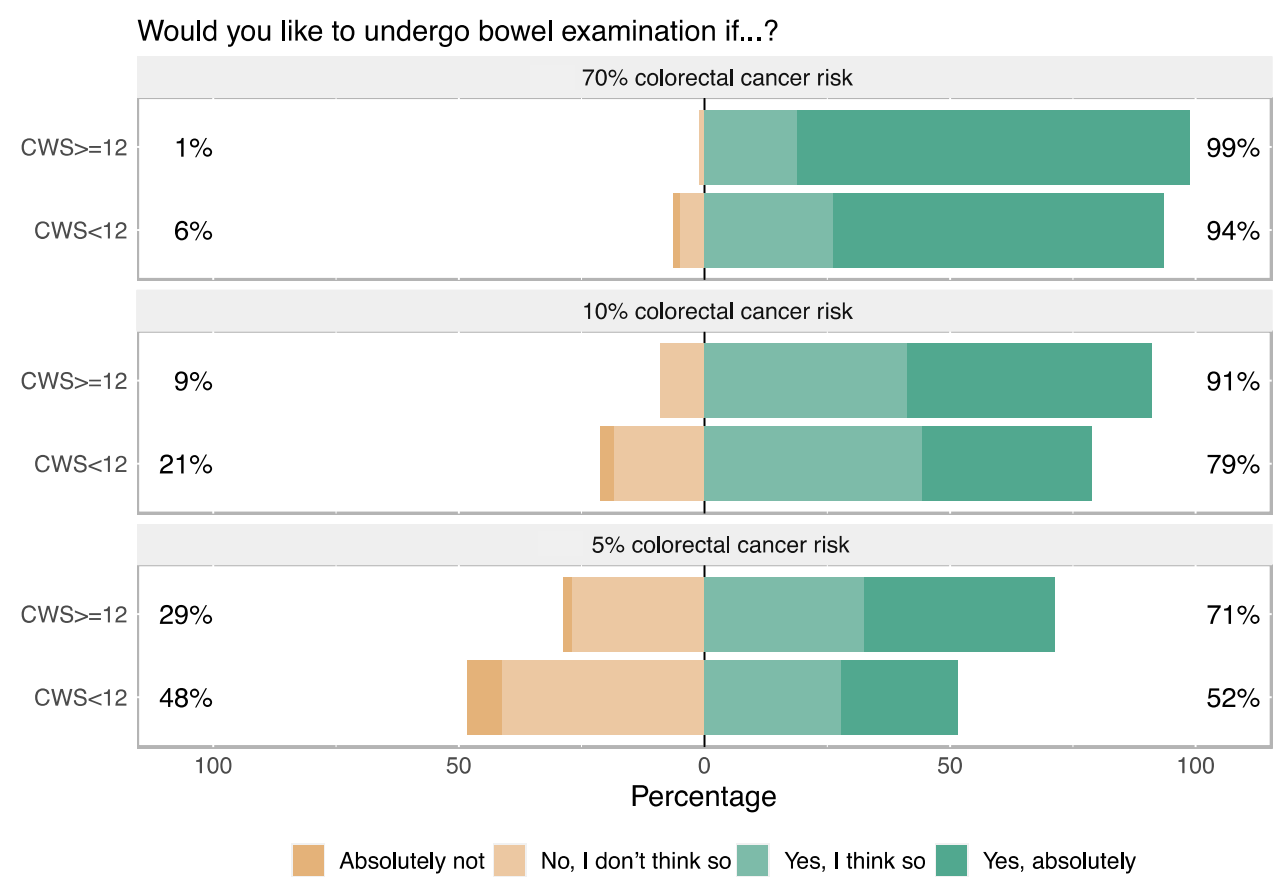

Figure 3. Intention to participate in colonoscopy screening at three levels of hypothetical colorectal cancer risk ( $n=853$, without cancer history). The scenarios presented three levels risk with the corresponding colonoscopy exam intervals: $5 \%$ lifetime risk with one-time colonoscopy, $10 \%$ lifetime risk with colonoscopy every five years, and $70 \%$ with colonoscopy every second year. Differences between the proportion of respondents with high and low cancer worry were significant in all three scenarios ( $p<0.001$ for bars in the two bottom panels and $p=0.025$ for bars in the top panel).

\section{Discussion}

In the present study, we investigated cancer worry levels in a population-based sample of the Swedish public aged between 18 and 74 years. We outlined both six- and eight-item CWS data and provide sample characteristics on gender, age, education, having children or not, country of birth, and personal cancer history. We also reported the prevalence and factors associated with cancer worry in both individuals with and without a personal cancer history and in the full heterogenous population-based sample. Finally, we analyzed how cancer worry scores are associated with the intention to undergo a colonoscopy screening at three different levels of hypothetical lifetime risk of colorectal cancer. Each risk level included a description of the interval of surveillance recommended in the case of hereditary risk.

Comparison and interpretation of CWS-derived data from different contexts are challenging due to a large variation in instruments and number of CWS-items used throughout the literature [7,9]. Different phrasings of items, varying Likert scales [23,24], inconsistent presentation of the data [7], and lack of population-based norm data have hampered overall comparisons. To the best of our knowledge, this is the first study describing populationbased norm CWS data in a Scandinavian population. This report of six- and eight-item CWS data with sample characteristics may help to inform future research on cancer worry, health-related behavior, and the clinical utility of the CWS scale.

\subsection{Cancer Worry in the General Population and in Those without a Cancer History}

The mean six-item CWS score in our full sample (9.61, SD 2.87) is similar to that reported in a somewhat comparable sample; this was a Spanish population of citizens aged 50 years and older recruited at primary health care and surveyed with the same six-item instrument (mean 9.3, SD 3.1) [25]. However, mean CWS scores were lower (7.1-8.8) in another study recruiting patients from primary health care for genetic testing for colorectal cancer risk in Australia [26]. 
In our data, respondents with a personal cancer history scored significantly higher on the six-item CWS than the larger unaffected group (mean 11.00). In previously published data on the six-item CWS, the mean scores among cancer survivors ranged from 9.0 for prostate cancer [4] to 8.4-9.2 for colorectal cancer [27] to 11.2 for breast cancer [4]. In this context, our subgroup of affected individuals appears to have scored in the upper interval of the cancer worry spectrum. Importantly, our subgroup of cancer-affected individuals was small $(n=82)$, self-reported, and not verified.

The mean eight-item CWS score in women was 13.96 (SD 4.14) and was 13.74 (SD 3.95) in women with no cancer history. In a recent study on curatively treated breast cancer patients, the mean values were 13.2-14.8 [28], whereas a study of women with newly diagnosed ovarian cancer reported a mean value of 17 [29]. In a Turkish study of women referred to a colonoscopy after a positive screening result, an even higher mean value of 20 was reported [30].

Hence, on the group level, there is an overlap in mean values of cancer worry between unaffected and affected populations as well as between different cancer types within affected populations. A recent review suggests that depression, anxiety, and distress among long-term cancer survivors do not significantly differ from the general population [31]. Although these concepts are not identical with cancer worry, they are closely related aspects in mental wellbeing and may hint at a pattern that is also valid for cancer worry.

\subsection{Gender Differences in Cancer Worry}

In previous research on cancer-affected populations [25,32] and in colorectal cancer screening participants [33], women report a higher cancer worry compared to men. This gender difference in cancer worry is confirmed in our population-based data. In a study using another instrument and sampling 2615 cancer survivors, female gender was found to be a strong predictor of fear of cancer recurrence while the type of cancer did not significantly affect fears [1]. Thus, gender appears to be an important determinant of cancer worry and should therefore be taken into consideration in future research on cancer worry, such as in the selection of matched controls, especially in patient groups with a skewed gender distribution.

\subsection{What Constitutes "Clinically Relevant" Cancer Worry?}

One previous approach to identifying "clinically relevant" cancer worry has been to use cut-offs dichotomizing respondents into high and low cancer worry groups [4,9]. In a re-validation study of the six-item CWS, severe fear of cancer recurrence was observed in $29.7 \%$ of patients with gastro-intestinal stromal tumors and colorectal, breast or prostate cancer survivors [4]. If the same suggested cut-off ( $\geq 12$ total score) is applied to our six-item CWS data, $21 \%$ of the respondents without a personal cancer history would be categorized as having "high cancer worry" (Table 1).

Studies with the eight-item CWS and using the suggested cut-off ( $\geq 14$ total score) [9] have identified high cancer worry in 31\% of breast cancer survivors [9], 38\% of CRC survivors [21], 33\% of pancreatic ductal adenocarcinoma surveillance participants [16], and $47 \%$ of TP53-mutation carriers [34]. If applying the same suggested cut-off ( $\geq 14$ total score) to the eight-item CWS in our study, $40 \%$ of the unaffected sample would be categorized as having "high cancer worry" (47\% of women and 33\% of men). The high proportion of individuals from the public scoring in the "high cancer worry" range raises the question of whether these cut-offs are suitable for determining "clinically relevant" cancer worry. This highlights the need for population norm data as a reference when interpreting CWS scores from patients $[16,33]$ and warrants the further investigation of cancer worry levels in more heterogeneous samples.

\subsection{Cancer Worry and Intention to Undergo Colonoscopy}

Public awareness of CRC risk and screening benefits has been shown to be low in Europe, and, overall, Swedes report an average interest in screening compared to other 
European countries [35]. Cancer worry has been described both as a motivator and as a barrier for screening uptake $[7,36]$. Two explanations have been proposed for these discordant observations. Firstly, an inverted u-shaped relationship between cancer worry and screening uptake has been proposed where moderate worry levels correlate with higher screening uptake, while very low and severe cancer worry both reduce screening participation $[7,25,37]$. Secondly, different components of fear may act in opposite directions on screening adherence. Fear of the screening modality itself (i.e., colonoscopy exam) could reduce screening uptake, while general worry about cancer seems to motivate screening participation $[8,17,38]$. The relationship between worry and screening intentions is thus influenced by a number of parallel factors, several of which seem to be mediated through constructs in the health belief model [12].

In our study, high cancer worry was associated with higher intention to undergo a colonoscopy. As we do not see any un-linear association between cancer worry and colonoscopy intention (Figure 2), our data support the notion that the CWS instrument may in fact measure general cancer worry/fear of cancer recurrence without the confounder "fear of the screening modality". In addition, intention to undergo screening increased with higher hypothetical lifetime risk of colorectal cancer despite a clear description of the corresponding increases in frequency of colonoscopies. This is in line with results from a clinical RCT study in Scotland where reported risk level perception was a significant factor in colonoscopy screening intention [39].

\subsection{Study Limitations}

This study has several limitations that should be considered. Of the 1800 individuals invited, 990 respondents entered the survey, 13 blank answers were excluded, and another 34 were incomplete and excluded due to missing data. The participation rate of $52 \%(n=943)$ is comparable with current rates in other publicly funded surveys internationally [40] but nonresponse bias may still have affected our data. To minimize the risk of self-selection bias, the invitation to the survey was neutral and did not disclose the topic beforehand as the term "cancer" has a known deterring effect [17], perhaps especially so in people with higher cancer worry.

Generalizations obtained from our data should be made with caution as our sample characteristics differed compared to both non-respondents and the Swedish population at large (Tables S5 and S6 in Supplementary Information). Our sample had an overrepresentation of people of older age, being born in Sweden, and with higher education.

The choice of age group in our sample and the screening modality in our scenarios was governed by the aim to offer norm data for comparison of cancer worry and screening interest in both public samples and for specific high-risk patient groups who may be offered colonoscopies due to increased cancer risk.

We measured intention to undergo a colonoscopy in hypothetical colorectal cancer risk scenarios, and consideration of the so-called "intention-behavior gap" described in social psychology is warranted [41]. As positive intentions are realized only half of the time while negative intentions are almost always predictive of behavior, our findings should be considered in light of this possibility.

We also acknowledge that our cross-sectional design limits our analysis because recent data suggest worry levels can fluctuate over time. In a one-year follow-up study of women with breast cancer, over $50 \%$ of respondents reported both high and low cancer worry when completing regular monthly assessments [28]. However, in other larger reviews, the fear of cancer recurrence was found to be stable over time [2], and the heterogeneous nature of our population-based sample may display a more even trend of worry than the data from cancer patients who have recently experienced disease and emotional strain.

\subsection{Clinical Implications}

This report offers clinicians and researchers a resource for age- and gender-matched comparisons of cancer worry data as a baseline reference from a heterogeneous general 
population. As our data show a substantial proportion of the public scoring in the "high cancer worry" range, further investigation of the cut-offs for clinically relevant cancer worry may be warranted in order to direct supportive resources to patients with the greatest needs. Moreover, as recent results suggest that cancer worry may fluctuate during the course of cancer treatment [28], future studies using longitudinal designs would be of interest to investigate the possible changes in worry levels over time in affected patients and high-risk individuals. We agree with the authors of the longitudinal breast cancer study who suggest a stepwise model wherein repeated measures could identify those in need of further interventions due to severe cancer worry at levels negatively affecting quality of life and daily functioning.

\section{Conclusions}

In this cross-sectional study of a Swedish population-based sample, female gender and personal cancer history were associated with higher cancer worry. However, cancer worry levels in our unaffected population were comparable to previous findings in cancer patients and survivors, suggesting that the psychological aspects of worry about cancer affect both patients and the public. Among those with high cancer worry, a larger proportion reported an intention to participate in a colonoscopy screening exam, and the willingness to undergo a screening increased in scenarios with higher risks of cancer. Our data support the idea that elevated cancer worry motivates health-related screening intention.

Supplementary Materials: The following three sections of supporting information can be found in https: / / www.mdpi.com/article/10.3390/cancers14040918/s1, Supplementary file 1: Figure S1: Histogram of 8-item CWS score in respondents without personal cancer history; Figure S2: Histogram of the 6-item (mean 9.61, median 9) and 8-item CWS scores (mean 13.26, median 13) in the populationbased sample; Table S1: The Cancer Worry Scale (translated to English); Table S2: The original cancer worry scale items (in Swedish); Table S3: The CRC screening-scenarios (translated to English); Table S4: 8-item CWS scores in participants without personal cancer history; Table S5: Characteristics of respondents and non-respondents; Table S6: Characteristics of the respondents compared with the Swedish population aged 18-74 during 2018; Table S7: Scores of the 6-item CWS in the populationbased sample; Table S8: Scores of the 8-item CWS in the population-based sample. Supplementary file 2: Copy of the survey invitation distributed to potential respondents in both original Swedish wording and in an English translation.

Author Contributions: Conceptualization, A.R., S.H., B.V.G. and A.A.; methodology, A.R., A.A., C.H., B.N.H. and S.H.; validation, A.A., C.H. and A.R.; formal analysis, B.N.H., J.M., A.A., B.V.G., S.H. and A.R.; investigation, A.A., J.M., C.H. and A.R.; data curation, C.H., B.N.H. and A.R.; writingoriginal draft preparation, A.A., J.M., C.H. and A.R.; writing-review and editing, A.R., B.N.H., S.H., B.V.G., A.A., J.M. and C.H.; visualization, B.N.H., C.H. and A.R.; supervision, A.R. and S.H.; project administration, A.R. and C.H.; funding acquisition, A.R., C.H. All authors have read and agreed to the published version of the manuscript.

Funding: This work was financed by the Swedish Research Council for Health, Work Life and Welfare (FORTE) under grant 2018-00964. The funders had no role in the design of the study; in the collection, analyses, or interpretation of data; in the writing of the manuscript, or in the decision to publish the results.

Institutional Review Board Statement: This study was approved by The Regional Ethical Review Board in Umeå [Dnr: 2016/345-31 and 2018/287-32].

Informed Consent Statement: Informed consent was obtained from all subjects involved in the study. Participation in the panel was voluntary, and participants were free to leave the panel at any time. No financial incentives were provided, neither upon registration to the panel or after response. LORE adheres to the General Data Protection Regulation (GDPR). Results were stored in encrypted files and delivered as anonymous data to the research team.

Data Availability Statement: Both data and scripts used to generate the analyses in this study are available upon request. We encourage other researchers or institutes to use our population-based norm data where applicable. 


\begin{abstract}
Acknowledgments: The authors would like to thank all survey participants for their contributions and the Laboratory of Opinion Research at University of Gothenburg for collaboration. The authors also thank Maria Wing for essential admin support.
\end{abstract}

Conflicts of Interest: The authors have no conflict of interest to declare.

\title{
References
}

1. Van de Wal, M.; van de Poll-Franse, L.; Prins, J.; Gielissen, M. Does fear of cancer recurrence differ between cancer types? A study from the population-based PROFILES registry. Psychooncology 2016, 25, 772-778. [CrossRef] [PubMed]

2. Simard, S.; Thewes, B.; Humphris, G.; Dixon, M.; Hayden, C.; Mireskandari, S.; Ozakinci, G. Fear of cancer recurrence in adult cancer survivors: A systematic review of quantitative studies. J. Cancer Surviv. 2013, 7, 300-322. [CrossRef] [PubMed]

3. Loescher, L.J. Cancer worry in women with hereditary risk factors for breast cancer. Oncol. Nurs. Forum 2003, 30, 767-772. [CrossRef]

4. Custers, J.A.E.; Kwakkenbos, L.; van de Wal, M.; Prins, J.B.; Thewes, B. Re-validation and screening capacity of the 6-item version of the Cancer Worry Scale. Psychooncology 2018, 27, 2609-2615. [CrossRef] [PubMed]

5. Jensen, J.D.; Bernat, J.K.; Davis, L.A.; Yale, R. Dispositional cancer worry: Convergent, divergent, and predictive validity of existing scales. J. Psychosoc. Oncol. 2010, 28, 470-489. [CrossRef] [PubMed]

6. Koitsalu, M.; Eklund, M.; Adolfsson, J.; Sprangers, M.A.G.; Gronberg, H.; Brandberg, Y. Predictors of participation in risk-based prostate cancer screening. PLoS ONE 2018, 13, e0200409. [CrossRef] [PubMed]

7. Hay, J.L.; Buckley, T.R.; Ostroff, J.S. The role of cancer worry in cancer screening: A theoretical and empirical review of the literature. Psycho-Oncology 2005, 14, 517-534. [CrossRef] [PubMed]

8. Vrinten, C.; Waller, J.; von Wagner, C.; Wardle, J. Cancer fear: Facilitator and deterrent to participation in colorectal cancer screening. Cancer Epidemiol. Biomark. Prev. 2015, 24, 400-405. [CrossRef]

9. Custers, J.A.; van den Berg, S.W.; van Laarhoven, H.W.; Bleiker, E.M.; Gielissen, M.F.; Prins, J.B. The Cancer Worry Scale: Detecting fear of recurrence in breast cancer survivors. Cancer Nurs. 2014, 37, E44-E50. [CrossRef]

10. Yang, Y.; Li, W.; Wen, Y.; Wang, H.; Sun, H.; Liang, W.; Zhang, B.; Humphris, G. Fear of cancer recurrence in adolescent and young adult cancer survivors: A systematic review of the literature. Psychooncology 2019, 28, 675-686. [CrossRef]

11. Tilburt, J.C.; James, K.M.; Sinicrope, P.S.; Eton, D.T.; Costello, B.A.; Carey, J.; Lane, M.A.; Ehlers, S.L.; Erwin, P.J.; Nowakowski, K.E.; et al. Factors influencing cancer risk perception in high risk populations: A systematic review. Hered. Cancer Clin. Pract. 2011, 9, 2. [CrossRef]

12. Wardle, J.; Sutton, S.; Williamson, S.; Taylor, T.; McCaffery, K.; Cuzick, J.; Hart, A.; Atkin, W. Psychosocial influences on older adults' interest in participating in bowel cancer screening. Prev. Med. 2000, 31, 323-334. [CrossRef] [PubMed]

13. Lerman, C.; Daly, M.; Masny, A.; Balshem, A. Attitudes about genetic testing for breast-ovarian cancer susceptibility. J. Clin. Oncol. 1994, 12, 843-850. [CrossRef] [PubMed]

14. Douma, K.F.; Aaronson, N.K.; Vasen, H.F.; Gerritsma, M.A.; Gundy, C.M.; Janssen, E.P.; Vriends, A.H.; Cats, A.; Verhoef, S.; Bleiker, E.M. Psychological distress and use of psychosocial support in familial adenomatous polyposis. Psychooncology 2010, 19, 289-298. [CrossRef]

15. Lerman, C.; Trock, B.; Rimer, B.K.; Jepson, C.; Brody, D.; Boyce, A. Psychological side effects of breast cancer screening. Health Psychol. 1991, 10, 259-267. [CrossRef]

16. Konings, I.C.; Harinck, F.; Kuenen, M.A.; Sidharta, G.N.; Kieffer, J.M.; Aalfs, C.M.; Poley, J.W.; Smets, E.M.; Wagner, A.; van Rens, A.; et al. Factors associated with cancer worries in individuals participating in annual pancreatic cancer surveillance. Fam. Cancer 2017, 16, 143-151. [CrossRef]

17. Vrinten, C.; van Jaarsveld, C.H.; Waller, J.; von Wagner, C.; Wardle, J. The structure and demographic correlates of cancer fear. BMC Cancer 2014, 14, 597. [CrossRef]

18. Bresner, L.; Banach, R.; Rodin, G.; Thabane, L.; Ezzat, S.; Sawka, A.M. Cancer-related worry in Canadian thyroid cancer survivors. J. Clin. Endocrinol. Metab. 2015, 100, 977-985. [CrossRef]

19. Martinsson, J.; Andreasson, M.; Johansson, J.; Holgersson, E. Technical Report Citizen Panel 31-2018; University of Gothenburg, LORE: Gothenburg, Sweden, 2018.

20. Andersson, A.; Hawranek, C.; Öfverholm, A.; Ehrencrona, H.; Grill, K.; Hajdarevic, S.; Melin, B.; Tham, E.; Hellquist, B.N.; Rosén, A. Public support for healthcare-mediated disclosure of hereditary cancer risk information: Results from a population-based survey in Sweden. Hered. Cancer Clin. Pract. 2020, 18, 18. [CrossRef]

21. Custers, J.A.E.; Gielissen, M.F.M.; Janssen, S.H.V.; de Wilt, J.H.W.; Prins, J.B. Fear of cancer recurrence in colorectal cancer survivors. Supportive Care Cancer 2016, 24, 555-562. [CrossRef] [PubMed]

22. R Core Team. R: A Language and Environment for Statistical Computing; R Project for Statistical Computing: Vienna, Austria, 2018; Available online: https:/ / www.R-project.org/ (accessed on 12 January 2022).

23. Timur Taşhan, S.; Uçar, T.; Aksoy Derya, Y.; Nacar, G.; Erci, B. Validity and Reliability of the Turkish Version of the Modified Breast Cancer Worry Scale. Iran. J. Public Health 2018, 47, 1681-1687.

24. Smits, S.; Boivin, J.; Menon, U.; Brain, K. Influences on anticipated time to ovarian cancer symptom presentation in women at increased risk compared to population risk of ovarian cancer. BMC Cancer 2017, 17, 814. [CrossRef] [PubMed] 
25. Hidalgo, J.L.; Sotos, J.R.; Herraez, M.J.; Rosa, M.C.; Lopez, J.L.; Ortiz, M.P. Factors Associated With Cancer Worry Among People Aged 50 or Older, Spain, 2012-2014. Prev. Chronic Dis. 2015, 12, E226. [CrossRef] [PubMed]

26. Saya, S.; McIntosh, J.G.; Winship, I.M.; Clendenning, M.; Milton, S.; Oberoi, J.; Dowty, J.G.; Buchanan, D.D.; Jenkins, M.A.; Emery, J.D. A Genomic Test for Colorectal Cancer Risk: Is This Acceptable and Feasible in Primary Care? Public Health Genom. 2020, 23, 110-121. [CrossRef]

27. Qaderi, S.M.; Swartjes, H.; Vromen, H.; Bremers, A.J.A.; Custers, J.A.E.; de Wilt, J.H.W. Acceptability, quality of life and cost overview of a remote follow-up plan for patients with colorectal cancer. Eur. J. Surg. Oncol. 2021, 47, 1637-1644. [CrossRef] [PubMed]

28. Custers, J.A.; Kwakkenbos, L.; van der Graaf, W.T.; Prins, J.B.; Gielissen, M.F.; Thewes, B. Not as Stable as We Think: A Descriptive Study of 12 Monthly Assessments of Fear of Cancer Recurrence Among Curatively-Treated Breast Cancer Survivors 0-5 Years After Surgery. Front. Psychol. 2020, 11, 580979. [CrossRef]

29. Van de Beek, I.; Smets, E.M.A.; Legdeur, M.A.; de Hullu, J.A.; Lok, C.A.R.; Buist, M.R.; Mourits, M.J.E.; Kets, C.M.; van der Kolk, L.E.; Oosterwijk, J.C.; et al. Genetic counseling of patients with ovarian carcinoma: Acceptance, timing, and psychological wellbeing. J. Community Genet. 2020, 11, 183-191. [CrossRef] [PubMed]

30. Uner, F.O.; Korukcu, O. A prevalence and psychometric study on fear of cancer in women with abnormal cervical cytology undergoing colposcopy. Psycho-Oncology 2020, 29, 1850-1855. [CrossRef]

31. Brandenbarg, D.; Maass, S.; Geerse, O.P.; Stegmann, M.E.; Handberg, C.; Schroevers, M.J.; Duijts, S.F.A. A systematic review on the prevalence of symptoms of depression, anxiety and distress in long-term cancer survivors: Implications for primary care. Eur. J. Cancer Care 2019, 28, e13086. [CrossRef]

32. McQueen, A.; Vernon, S.W.; Meissner, H.I.; Rakowski, W. Risk perceptions and worry about cancer: Does gender make a difference? J. Health Commun. 2008, 13, 56-79. [CrossRef]

33. Vermeer, N.C.A.; van der Valk, M.J.M.; Snijders, H.S.; Vasen, H.F.A.; Gerritsen van der Hoop, A.; Guicherit, O.R.; Liefers, G.J.; van de Velde, C.J.H.; Stiggelbout, A.M.; Peeters, K. Psychological distress and quality of life following positive fecal occult blood testing in colorectal cancer screening. Psycho-Oncology 2020, 29, 1084-1091. [CrossRef] [PubMed]

34. McBride, K.A.; Ballinger, M.L.; Schlub, T.E.; Young, M.A.; Tattersall, M.H.N.; Kirk, J.; Eeles, R.; Killick, E.; Walker, L.G.; Shanley, S.; et al. Psychosocial morbidity in TP53 mutation carriers: Is whole-body cancer screening beneficial? Fam. Cancer 2017, 16, 423-432. [CrossRef]

35. Keighley, M.R.; O’Morain, C.; Giacosa, A.; Ashorn, M.; Burroughs, A.; Crespi, M.; Delvaux, M.; Faivre, J.; Hagenmuller, F.; Lamy, V.; et al. Public awareness of risk factors and screening for colorectal cancer in Europe. Eur. J. Cancer Prev. 2004, 13, 257-262. [CrossRef]

36. Willis, A.M.; Smith, S.K.; Meiser, B.; Ballinger, M.L.; Thomas, D.M.; Young, M.A. Sociodemographic, psychosocial and clinical factors associated with uptake of genetic counselling for hereditary cancer: A systematic review. Clin. Genet. 2017, 92, 121-133. [CrossRef]

37. Andersen, M.R.; Smith, R.; Meischke, H.; Bowen, D.; Urban, N. Breast Cancer Worry and Mammography Use by Women with and without a Family History in a Population-based Sample. Cancer Epidemiol. Biomark. Prev. 2003, 12, 314-320.

38. Vrinten, C.; McGregor, L.M.; Heinrich, M.; von Wagner, C.; Waller, J.; Wardle, J.; Black, G.B. What do people fear about cancer? A systematic review and meta-synthesis of cancer fears in the general population. Psycho-Oncology 2017, 26, 1070-1079. [CrossRef] [PubMed]

39. Digby, J.; O'Carroll, R.E.; Chambers, J.A.; Steele, R.J.C. The impact of hypothetical PErsonalised Risk Information on informed choice and intention to undergo Colorectal Cancer screening colonoscopy in Scotland (PERICCS)-a randomised controlled trial. BMC Med. 2020, 18, 285. [CrossRef] [PubMed]

40. Hedlin, D. Is there a 'safe area' where the nonresponse rate has only a modest effect on bias despite non-ignorable nonresponse? Int. Stat. Rev. 2020, 88, 642-657. [CrossRef]

41. Sheeran, P. Intention-Behavior Relations: A Conceptual and Empirical Review. Eur. Rev. Soc. Psychol. 2002, 12, 1-36. [CrossRef] 